\title{
Infrastructure planning for sustainable cities
}

\author{
Michael Neuman, Sydney
}

\section{Introduction}

Sustainable urban planning frameworks also apply to «critical infrastructures». This article presents a framework for better linking the planning of cities and their critical infrastructure so that they will become more sustainable. The first large scale city planning operations in history were infrastructure interventions. They range from the first known water management systems that separated drinking water from waste water in Indus Valley cities five millennia ago to the aqueducts and streets of ancient Rome. More recently, from the infrastructure-led rebuilding of Paris and Barcelona in the 1850 s that gave rise to modern city planning; to the highways, high speed rail, airports, and internet of the global city. All city planning was abetted by infrastructure. Transitions from one historical era to the next were marked by leaps in city building and infrastructure inventions. Infrastructures enabled cities at a scale and density not possible without them. Infrastructures are so intrinsic to urban life that power, water, transportation, and telecommunications networks are called «critical infrastructures».

\section{Linking urban planning and infrastructure network planning}

Infrastructure is vital to the creation of sustainable cities, and proper planning is vital to the creation of sustainable infrastructure. This article argues for the integration of the disparate strands of infrastructure and urban planning (planning is understood as a professional activity conducted by a wide range of disciplines in a wider range of institutions - see section 16) into a coherent and sustainable method that can be applied at any scale. Currently, infrastructure systems tend to be planned individually, in isolation from each other and from urban planning. This entails great social, economic and ecological costs, greater than if unplanned, and involves higher risk (Altshuler \& LuberofF 2003; Flyvberg, Bruzelius \& Rosengatter 2003).

The life cycle approach to infrastructure planning proposed here enables practitioners from any discipline to understand the complete life cycle from their discipline's point of view. It further enables different disciplines to work together to ensure that planning is longterm, comprehensive and sustainable. Responsive life cycle planning contextualizes engineering and finance so that technical and monetary considerations are part of the decision making processes, along with environmental, social, economic, aesthetic, security, and other criteria. The framework presented here calls for a collaborative, multi-level planning process and recognises that the process will be culturally determined, institutionally bound, and politically motivated (FLYVBERG et al. 2003; Healey 2010; InNes, Booher \& Di VitTorio 2011).

After briefly describing key terms, the article turns to a detailed description of the different aspects that would need to be integrated into infrastructure network planning to ensure that this planning is integrative and adaptive to various contexts.

\section{Life cycle/demand-capacity approach to infrastructure network planning}

The approach entails two steps. First is a demandcapacity analysis of the geographic area being planned, to determine the overall amount of infrastructure services needed at a specified time in the future. In contrast, infrastructure planning and research into it is now almost exclusively supply-side (Dowall 2001; MaYs 2002). Second is conducting a life cycle analysis of an infrastructure network, which permits sustainable stewardship over its entire working life. While this has been suggested and tested, it appears that they have rarely been implemented on a network scale (KotajI el al. 2003).

By linking these two steps, infrastructure planning can yield more sustainable outcomes over the long term by explicitly accounting for economic, social, and ecological resources and constraints. In this context, sustainability refers to the rates of the inter-related processes that keep a place such as a city region alive and healthy that must be maintained (sustained) over time without exceeding the innate, natural ability of the place and its surroundings to support the processes. This includes the ability of the surroundings to absorb the impacts of the processes - their resilience.

Fundamental to life cycle planning is to treat infrastructure as having a life span. Each infrastructure has its life cycle. This entails a long term view of infrastructure (maybe hundreds of years) and their consequences in urban areas. This goes far beyond the time scales commonly adopted in planning today, in which short term is one election or accounting cycle (one 
to five years), and long term ranges between ten and thirty years. A hypothesis worth testing is that curtailing time horizons has led to the decrease of practices that are sustainable.

\section{Demand-capacity analysis and life cycle planning}

Demand-capacity analysis determines the demand for all infrastructure systems at a specific future time in a determinate geographic area, consistent with ecological, social, and economic capacities of that area. Life cycle planning permits the sustainable stewardship of infrastructure networks and facilities over their entire working lives. Taken together, demand-capacity analysis and life cycle planning let planners integrate various «layers» of settlements - natural systems, infrastructure systems, and superstructures (visible urban form) - into a proposed approach to infrastructure planning that will be able to ensure greater sustainability of network systems over the long term.

\section{Demand-capacity management}

Demand-capacity management is a balanced growth management strategy that apportions infrastructure over time to stimulate growth where and when it is desired and reign it in where and when it is not. It designates a graduated set of areas (districts or zones) in which the scale and timing of critical infrastructures (water, sewerage, transportation, and telecommunications) match planned development expectations. Demand-capacity management builds on the fact that urban development is the sum of the interactions of a wide range of processes that occur over time. It is not an absolute science, and projections of population, employment, and infrastructure demand are uncertain estimates. It integrates two analytical methods in a specific geographic area: carrying capacity analysis in the McHargian tradition, and comprehensive infrastructure needs assessment in the New Jersey State Plan (McHarg 1969; New Jersey State Planning Commission 2001). There are nine steps that guide demand-capacity management for infrastructure.

\section{Step 1: Establish carrying capacity levels}

Establish carrying capacity levels of natural and social environments to support urban development. This analysis is based on the ecological planning principles forwarded by McHARG (1969). Ecological carrying capacity is the ability of all the habitats in a region to support human settlement of a given size and density. It concerns water supply, air quality, soil quality, slopes, etc. to support urban development, the functional integrity of ecosystems, and survivability of individual species. For example, an aquifer with a certain capacity and known average recharge rate can sustainably support a population, given average consumption rates per person of that population.

Ecological carrying capacity is a conceptual model that has been applied to measure the capacity of a specific place to sustain urban development. A jurisdiction such as a municipality or province allocates total projected growth after adding the capacities of three types of areas to support growth: 1) existing communities, 2) new communities, 3) un- or less-developed environs (exurbs, farmlands, parks, habitats).

Existing Community Capacity is calculated by determining the amount of growth that can be sustained in each existing (developed) community, taking infrastructural, environmental, social, and fiscal capacities into account.

New Community Capacity is calculated by determining the amount of growth that can be sustained in new communities based on infrastructural, environmental, social, and fiscal capacities. This calculation occurs after subtracting the growth to be accommodated in the existing communities.

Environs Capacity is calculated by first determining the maximum capacity based on natural, agricultural, rural, infrastructural, and other systems' capacities. This carrying capacity is calculated after subtracting the growth allocated to existing and new communities as calculated in the two prior steps.

Demand-capacity analysis matches projected population, employment, and housing levels with existing and projected infrastructural, environmental, social, and fiscal capacities to support growth. This method allocates growth spatially in a sustainable manner consistent with the capacities of various systems to support it.

\section{Step 2: Establish levels of service standards}

Levels of service indicate a minimum standard level to be maintained by an infrastructure or utility service provider. Sustaining reliable levels of service for users is the goal of any infrastructure service provider.

\section{Step 3: Analyze capacities of existing and programmed infrastructure}

Analyze the capacities of existing and planned infrastructure networks and facilities based on the levels of service standards from the preceding step. This is done by multiplying per unit levels of service by the number of units of infrastructure delivering the service (number of vehicles in a metro or subway fleet, number of reservoirs and aquifers, each with its rated capacity, for example). The sum is the total capacity for each infrastructure. The calculation takes into account 
both currently existing networks or facilities, as well as planned networks and facilities.

\begin{abstract}
Step 4: Determine population, employment, and housing projections

Determine population, employment, and housing projections for a specified future date in the planning area. The drawback of using official data projections is that they only project several decades into the future. The prudence of this limitation stems from the uncertainty of factors that affect population, job, and housing growth. The relatively short-term time accuracy of these projections complicates the calculation of sustainable life-cycles, given that the service life of an infrastructure such as a sewer system, bridge, or road may be centuries long.
\end{abstract}

Demand-capacity management assumes that the amount of growth that will occur in the future is determined by a combination of forces: market, demographic, social, and government policy. Infrastructure planning based on demand-capacity management may accept the amount of projected growth as a given, focusing less on the actual quantity, but instead managing the location, density, and timing of projected growth.

Step 5: Calculate the future demand for infrastructure Calculate the future demand for infrastructure using the population, employment, and housing projections of Step 4 and the levels of service desired in Step 2, according to the formula in Equation 1, taking into account reductions due to demand management.

\section{Equation 1:}

demand $d=$ number of units $\mathrm{x}$ demand per unit

units $u=$ population, or jobs, or households $\left(u_{p}, u_{j}, u_{h}\right)$ demand per unit (level of service) $=$ amount of infrastructure service provided per unit (for example litres per capita per day)

\section{Step 6: Compare future demand to existing capacity} Compare the anticipated future demand calculated in Step 5 to the existing and programmed infrastructure network and facility capacities calculated in Step 3 and the social and environmental carrying capacities from Step 1.

\section{Step 7: Determine whether growth can be sustainably supported}

If the anticipated demand for infrastructure calculated in Step 5 exceeds existing and programmed infrastructure capacities, this means that new infrastructure is needed. An alternative is to manage demand, or provide an alternative service. After demand management and other options are evaluated, if new infrastructure is determined to be needed, then analyze the environ- mental, social, and fiscal costs and impacts of expanding infrastructure capacity.

\section{Step 8: Calculate a sustainable level of demand}

Calculate an acceptable and sustainable level of demand for each infrastructure network and facility. Based on the analyses conducted in Steps 6 and 7, adjust desired levels of service (Step 2) and population, housing, and employment projections (Step 4) to calculate a politically acceptable and sustainable level of demand for each infrastructure network and facility.

\section{Step 9: Outputs of demand-capacity analysis as inputs to life cycle planning}

At scheduled, periodic moments in the future, assemble performance data of all phases of the life cycle and use them as inputs into re-evaluating the infrastructure system de novo.

\section{Demand management}

Demand management seeks to limit or otherwise control user demand of infrastructure services. Demand management shifts the focus of infrastructure from the provider to the consumer, and has been developed in most infrastructure fields, notably water, energy, and transportation (BAUMANN et al. 1998; TANATVANIT et al. 2003).

«Most policy assessments focus on the supply side of infrastructure planning. A common misstep is to prepare forecasts of need based on per capita estimates of consumption. These per capita indicative standards largely ignore price elasticity of demand, the effects of conservation, and technological change. (...) These strategies include using facilities more efficiently and raising prices to reduce demand for scarce infrastructure resources. If widely implemented, demand-management strategies can significantly reduce the cost of new infrastructure» (DOWALL 2001: ix).

Demand management poses a basic question: are there other ways to meet infrastructure needs without investing greater amounts of capital? Demand management initiatives include peak price increases and off-peak price reductions, congestion charges, providing alternatives, schedule shifting and load balancing, extending hours of operation to get more use of the same facility, sharing facilities, exploring multiple uses for the same facility, and reducing demand of scarce resources by recycling instead of waste disposal.

\section{Life cycle infrastructure planning}

Urban planning often reacts or responds to current demands, for example, by formulating a spatial plan to contain or deal with the impacts of rapid urban growth. 
However, it is possible, that before the plan is actually implemented, the growth spurt ends, the economy is in a downturn and infrastructure planning demands are fundamentally different.

In contrast, life cycle planning implies long term stewardship. Life cycle planning is a comprehensive system that covers the entire range of infrastructure planning, development, and operations - from the initial stage of demand assessment to the final stage of evaluation. What converts this sequence into a full cycle is the use of the final evaluation stage in the next iteration of the assessment stage, resuming the entire cycle. The life cycle should not be restrictively interpreted to be followed only in a linear sequence. Combinations or mergers of stages are possible, such as design-build and build-operate-transfer.

\section{Infrastructure demand assessment}

Preparing a long term infrastructure demand assessment creates baseline data to guide management decisions. A basic algorithm to conduct infrastructure demand assessments is represented by Equation 1 . Demand assessments measure two types of demand, new facilities and existing facilities. Demand for new facilities uses Equation 1. Existing demands can be organized into two categories: repairing/rehabilitating and bringing up to acceptable service standards. The integrated assessment model presented here includes three types of demand: new infrastructure, rehabilitation, and backlog.

New infrastructure covers new facilities and networks and the expansion of existing infrastructures that serve new development.

Rehabilitation of existing infrastructure includes recurring periodic activities to replace or improve existing infrastructure in order to keep it in service at specified levels of service standards. It includes routine scheduled maintenance plus overhaul and rehabilitation.

Backlog expenditures correct existing deficiencies to serve the existing population. It may include upgrades to infrastructure capacity to fill unmet needs resulting from past growth or other increases in infrastructure consumption. Filling backlog demand can also raise deficient levels of service to minimum levels.

\section{Programming}

Programming is the planning function that assigns a specified amount of an infrastructure service to a defined user population. It converts a long term demand assessment into a short term programme that indicates exactly how much service is delivered to whom, how, where, and when. The purpose of programming is to provide precise data for designers, cost accountants, and budgeters to proceed by preparing plans, designs, and budgets that permit construction.

In sum, the capital programme serves as the quantitative basis for the physical planning and design of infrastructure networks and facilities. The capital programme contains a composite listing of annual schedules and costs for the construction, overhaul, and/or expansion of infrastructure facilities over a medium term time horizon, typically four to six years. The capital programme translates standard need or demand equations for an entire infrastructure network into specific action agenda. When coupled with facility design, a capital programme links the demand assessment to the annual capital budget.

\section{Network design}

A distinction can be made between network design and facility design. Network design concerns physical structure - the form, function, and distribution in geographic space of the entire infrastructure network. Network types include the electric power grid, water supply system, city street grid, or the internet. What is referred to here as network design, can also be referred to as network planning. Listed below are six principles to consider for sustainable network design.

\section{a) Optimize the number of land uses and individual users served by each network}

This principle of infrastructure network design is a question of adding value through increasing accessibility through infrastructure. Cities exemplify this principle, and in particular, city centers. Higher urban densities are made possible by and in turn generate the need for more infrastructure - a city-infrastructure symbiosis. A goal of network design is to optimize connections.

\section{b) Facilitate the synergistic co-location of facilities}

Synergistic co-location builds on access optimization. An example is to link modes of transportation at a commuting hub in a city center or edge city, or at a logistics hub like a seaport, airport, or railport. It aims to enhance accessibility and permit the optimal selection of transport modes. Designs that enable synergistic co-location also amplify opportunities to share transport rights-of-way with other infrastructure networks.

\section{c) Share rights-of-way}

By sharing rights-of-way, infrastructure network design can cut infrastructure costs and support sustain- 
able development. In non-urban areas, sharing rightsof-ways ensures less dissection of natural habitats and saves costs for buying land, clearing vegetation, and maintenance. In urban areas, this principle helps save valuable land and encourage the co-location of infrastructures.

\section{d) Durability}

What if we demanded that infrastructures last (only) twice as long as those built by our historical predecessors? That would halve construction costs, plus increase long term sustainability. If aqueducts, canals, and buildings constructed two thousand years ago have lasted five hundred years or more, why do planners nowadays accept fifty year life spans? This principle calls for longer life spans for infrastructure in order to cut overall per annum investment costs, minimising impacts on the environment and population and decreasing maintenance costs by investing in durable systems. Durability increases service reliability and decreases maintenance and replacement costs, and the disruptions they cause.

\section{e) Permanence}

Permanence has to do with the persistence of an infrastructure and its impacts on place. Permanence draws upon durability, yet differs from the point of view of flexibility in use. An example is the persistent use of travel paths, initially by different species, and then by humans for different modes of transport. Thus, animal tracks and migration paths were transformed to human footpaths, developing into vehicle paths, then motorized vehicle paths before becoming roads, highways, and multi-lane freeways, occasionally supplanted or adjoined by public transit and railways. Some of these paths-into-superhighways have persisted for thousands of years. Such persistence provides a critical perspective on network design for sustainability. Permanence can sharpen our understanding of the consequences of the location and layout of infrastructure networks. A bridge over a river can fix the location of a city for millennia.

\section{f) Recyclability}

Converting obsolete or underused infrastructure is an art of creative foresight. The redesign of an obsolete network or facility is of interest when it would be otherwise too costly, harmful, or otherwise unsuitable to dismantle or recycle it. Examples include converting abandoned railroad tracks into hiking and biking trails, and the use of closed landfills as hilly parks, such as Mount Junk (Teufelsberg) in Berlin. The resourceful conversion of what some consider waste is key to what LyNCH called «wasting well» (1990). Recyclability can cut disposal costs, reduces toxic additions to waste streams, reduces mining and other material extraction costs, reduces manufacturing costs that use raw materials, and inspires creativity in infrastructure design, among other benefits.

\section{Life cycle cost accounting}

Once a network or facility is designed, its construction costs can be calculated. Life cycle cost accounting goes to the heart of sustainable infrastructure planning. An economic calculus is the predominant criterion by which capital investment decisions are made, regardless whether in the public or private sector. For infrastructure investments, the amount of debt available is based in part on the value of the infrastructure, for which accurate cost estimates are required. Consequently, how cost is calculated has a clear impact on investment willingness, and thus on investment returns. Under these conditions, an important way to introduce sustainability into capital investment decisions is through cost accounting.

A life cycle costing approach goes beyond traditional cost accounting methods by expanding costing methods to include calculations for all costs over the entire service life of a network or facility, in addition to still including those indicated by standard cost accounting. Life cycle costs include costs embodied in and occasioned by the infrastructure's physical plant: operations, scheduled maintenance, repair, replacement, and eventual decommissioning, recycling, and disposal. They further include anticipated costs of environmental impacts and social impacts. Life cycle costing is cradle-to-grave accounting that more completely encompasses all the costs associated with an infrastructure network (BARTELMUS 1994; BARTELMUS \& VAN TONGEREN 1994).

Life cycle costs include all the expenses that are expected over the working life of the infrastructure: from assessment and planning through programming, design, costing, budgeting, financing, construction, operations, maintenance, repair, rehabilitation, replacement, and evaluation/reassessment, which completes the cycle by returning to the start. The benefit of life cycle cost accounting is that the resultant monetary costs, when fed into a capital budget, permits all activities over the entire life cycle to be anticipated, planned, funded, and managed. Life cycle costs become the basis of life cycle budgets, which permits the calculation of sustainable streams of revenue to be generated and allocated throughout the service life of the infrastructure system.

\section{Life cycle budgeting}

The capital budget is a vital link between infrastructure planning and financing. A capital budget is a management tool that tracks and guides the income and expenditure of funds to construct capital projects. A life cycle capital budget indicates the costs to design, 
build, operate, and sustain the capital invested in infrastructure throughout its service life. For capital budgeting, detailed and specific planning, design, engineering, environmental, and social cost analyses are derived from a four to six year capital programme. A capital budget is typically a one to two year document that lists projects and their costs.

\section{The continuum of Maintenance, Rehabilitation, Replacement}

A common cause of infrastructure problems stems from deficiencies in maintenance. Study after study has reported failures due to disrepair, accidents leading to property loss, injury, and death, decreases in environmental quality, public health, economic output and productivity, as well as premature facility failure or retirement. The word repair is a general term inclusive of maintenance, rehabilitation, and reconstruction. By including these aspects into the life-cycle, it is hoped that they will receive greater attention in managerial and political agendas.

A well-developed Maintenance, Rehabilitation, and Reconstruction (MRR) System, if implemented fully and correctly, is expected to minimize physical deterioration and system down time while it maximises system performance and up time. MRR systems are operational support systems (OSS) and decision support systems (DSS). The two cited texts indicate the data requirements and other parameters needed to develop the database for an infrastructure maintenance decision support system (Hudson, HaAs \& Uddin 1997; MaYs 2002). Indicators used in MRR data bases serve as inputs into a comprehensive performance evaluation system (see next section). To improve MRR system management, it is possible to link an MRR database can be linked with a geographic information system (GIS). This allows the physical and operating conditions to be correlated with the spatial location of the facilities and conduits of infrastructure networks to improve management.

\section{Evaluation}

Evaluation tells any interested party how well an organization accomplishes its mission. For infrastructure, evaluation measures fall in three categories: monitoring the organization and its management, monitoring the physical condition of infrastructure, and monitoring the services provided. The comprehensive framework for a life cycle evaluation programme presented here applies to an infrastructure network, its services, and its organization. Linking evaluation to the life cycle planning process provides a complete data base that serves as an essential management tool.
Comprehensive assessment models that employ a greater number and wider variety of criteria to evaluate performance are becoming more common as agencies expand decision making criteria to include environmental and social factors in addition to economic and financial ones. As a result, infrastructure providers have expanded the scope of their assessment indices (DEL Borghi et al. 2009; World BANK 2004).

In developing a life cycle based evaluation programme for infrastructure, first select what to evaluate. Second, select standards or benchmarks to measure the performance of these items. After this, develop a database that arrays the items to be evaluated and their benchmarks according to a monitoring schedule over the entire life cycle. Next, conduct field evaluations by checking equipment condition, service performance, and organizational effectiveness. Then, analyze and interpret the field data. Finally, results and consequences for practise should be recorded in the data base if ongoing managerial and decision making processes are to profit from the evaluation.

Conducting a life cycle evaluation performs a number of functions for the infrastructure agency. It provides greater accountability to politicians, managers, owners, users, citizens, and interest groups. It increases organizational effectiveness by providing a comprehensive assessment framework to improve processes and information. It helps the organization's staff to plan and manage by offering benchmarks to focus attention and priorities. Evaluation programmes help legitimize and improve planning processes by providing performance targets. These targets apply internal discipline to the organization to hold management and employees accountable. Evaluation improves the communication of information by providing explicit goals, objectives, and performance measures. It assists in the preparation, update, and improvement of life cycle cost and benefit methodologies; and of MRR budgets and programmes. Good evaluation programmes help predict rates of equipment deterioration and possible failure, which assists MRR scheduling (HuDson, HAAs \& Uddin 1997; NEumann \& Markow 2004).

Evaluating infrastructure is an activity that can be waged on many fronts. Thus, infrastructure can be gauged on the basis of service performance (on-time, continuous availability, reliability), user satisfaction (ease of access and use, meets expectations, quality of experience), physical condition (structural integrity, load capacity, deterioration), safety (accidents, injury, property loss), and/or security (risk, vulnerability). Other criteria include contributions to society and the economy, its environmental, social, and other impacts on its surroundings, and the distributional equity of its accessibility. This list is suggestive and not limiting. 


\section{Underlying principles for a life cycle infrastructure framework}

To develop a comprehensive life cycle infrastructure evaluation framework, principles need to be identified to guide its formulation. These principles can be taken from suggestions propagated by academic, professional, industrial or governmental agencies who are increasingly working with life cycle and sustainability criteria. Well-documented life cycle and sustainable impact assessment methodologies include CARMONA \& Sieh (2004), Del Borghi et al. (2009), Kotaji et al. (2003), and Organization FOR ECONOMIC COOPERATION AND DEVELopment - OECD (2000).

\section{Comprehensive and synthetic life cycle infra- structure planning}

The life cycle approach to infrastructure planning enables practitioners from any discipline to understand the complete life cycle from their discipline's point of view. It situates disciplinary work in a long-term, comprehensive, and sustainable context. Thus an engineer can consider the multiple impacts of a network on the landscape and adjust the design accordingly. An engineer can also evaluate the environmental and energetic costs and impacts of the materials used. A budget analyst can collaborate with engineers to attain lowest life cycle costs that consider the full ramifications of an infrastructure system's construction, operations, and maintenance - and not merely materials and labour costs. A financial manager can work with budget analysts to fashion a life cycle financing process that provides a sustainable stream of money to pay for all the requirements of an infrastructure network throughout its service life. A politician can set the goals, evaluation criteria, priorities, and the legal-institutional framework for life cycle planning, and monitor them by legislative oversight. Urban planners coordinate the entire process by designing and managing processes that engage collaboration of all participants. Each participant and profession plays a role in the life cycle.

The aim of this framework is to plan sustainable infrastructure networks. The framework enables moving from critical infrastructure protection to critical infrastructure network planning and maintenance using the long term perspective of living with the contextual constraints of infrastructure networks in a region, that is, sustainably.

\section{References:}

Altshuler, A. \& D. Luberoff (2003): Mega-projects: The changing politics of urban public investment. Washington, DC: Brookings Institution Press.
BARTELMUS, P. (1994): Towards a framework for indicators of sustainable development. - New York: United Nations, Department for Economic and Social Information and Policy Analysis.

Bartelmus, P. \& J. van Tongeren (1994): Environmental accounting: An operational perspective. - New York: United Nations, Department for Economic and Social Information and Policy Analysis.

Baumann, D., Boland, J. \& W. Hanemann (1998): Urban water demand management and planning. New York: McGraw-Hill.

CARmona, M. \& L. SieH (2004): Measuring quality in planning: Managing the performance process. London: Spon Press.

Del Borghi, A., Gallo, M. \& M. Del Borghi (2009): A survey of life cycle approaches in waste management. - In: International Journal of Life Cycle Assessment 14, 7:597-610

Dowall, D. (2001): California's infrastructure policy for the $21^{\text {st }}$ century: Issues and opportunities. - San Francisco: Public Policy Institute of California.

Flyvberg, B., Bruzelius, N. \& W. Rosengatter (2003): Megaprojects and risk: An anatomy of ambition. New York: Cambridge University Press.

Healey, P. (2010): Making better places: the planning project in the twenty-first century. - New York: Palgrave Macmillan.

Hudson, R., HAAs, R. \& W. Uddin (1997): Infrastructure management: Integrating design, construction, maintenance, rehabilitation and renovation. - New York: McGraw-Hill.

InNes, J., Booher, D. \& S. Di VitTorio (2011): Strategies for megaregion governance: Collaborative dialogue, networks, and self-organization. - In: Journal of the American Planning Association 77, 1:55-67.

KotaJi, S., Schuurmans, A. \& S. Edwards (2003): Lifecycle impact assessment: The state-of-the-art. - Pensacola, FL: Society of Environmental Toxicology and Chemistry.

LyNCH, K. (1990):Wasting away. - San Francisco: Sierra Club Books.

MAYs, L. (ed.) (2002): Urban water supply handbook - New York: McGraw-Hill.

McHARG, I. (1969): Design with nature. - New York: Natural History Press.

Neumann, L. \& M. Markow (2004): Performancebased planning and asset management. - In: Public Works Management and Policy 8, 3: 156-161.

New Jersey State Planning Commission (2001): The New Jersey state development and redevelopment plan. - Trenton, NJ.

ORganization FOR ECONOMIC COOPERATION AND Development (2000): Towards sustainable development: Indicators to measure progress. Proceedings of the OECD Rome conference on sustainable development. - Paris: OECD.

Tanatvanit, S., Limmeechokchai, B. \& S. ChungPaI- 
BULPATANA (2003): Sustainable energy development strategies: Implications of energy demand management and renewable energy in Thailand. - In: Renewable and Sustainable Energy Reviews 7, 5: 367-395.

WORLD BANK (2004): Reforming infrastructure: Privatization, regulation, and competition. - Washington, DC: The World Bank.

\begin{abstract}
Infrastructure planning for sustainable cities Infrastructure is vital to the creation of sustainable cities, and proper planning is vital to the creation of sustainable infrastructure, including and in particular with reference to critical infrastructures. This article integrates several strands of infrastructure planning into an integrated and comprehensive approach applicable at any scale. The approach involves two steps: performing a demand-capacity analysis of the geographic area being planned, to determine the overall amount of infrastructure services needed at a specified future time; and conducting a life cycle analysis of an infrastructure network, which permits sustainable stewardship over the infrastructure's entire working life. This links infrastructure planning with urban planning and provides a quantitative basis for sustainable infrastructure.
\end{abstract}

Keywords: infrastructure planning, life cycle, demandcapacity management, urban planning, sustainable development

\section{Zusammenfassung: Infrastrukturplanung für nachhaltige Städte}

Infrastruktur ist wesentlich für die Herausbildung nachhaltiger Städte und nachhaltige Planung von kritischen Infrastrukturen. Dieser Artikel integriert verschiedene Ansätze der Infrastrukturplanung in eine umfassende Methode, welche sich auf jede geographische Grössenordnung anwenden lässt. Die vorgeschlagene Methode umfasst zwei Schritte. Dies sind erstens eine Nachfragekapazitäts-Analyse (demandcapacity analysis), um den zukünftigen Gesamtbedarf an Infrastrukturen für ein geplantes Gebiet zu bestimmen, zweitens eine Lebenszyklus-Analyse (life cycle analysis) eines Infrastrukturnetzes. Diese soll die nachhaltige Verwaltung dieser Infrastruktur auf deren gesamte Lebensdauer hin ermöglichen. Das Vorgehen verbindet Infrastrukturplanung mit Stadtplanung und bietet eine quantitative Basis für die Erstellung nachhaltiger Infrastrukturen.

Schlüsselwörter: Infrastrukturplanung, kritische Infrastruktur, Nachfragekapazitätsmanagement, Nachhaltige Entwicklung

\section{Résumé: Planifier les infrastructures pour des villes durables}

Les infrastructures sont vitales en matière de durabilité urbaine, de même qu'une planification est indispensable pour créer des infrastructures durables, notamment en ce qui concerne les réalisations les plus critiques. Cet article synthétise plusieurs courants de la littérature consacrée à la planification des infrastructures et propose une méthode intégrée et compréhensive applicable à n'importe quelle échelle. La méthode procède en deux étapes: en premier lieu, il s'agit d'examiner la demande et la capacité de l'aire géographique concernée et de déterminer les besoins de services liés aux infrastructures qui seront nécessaires dans le futur. En second lieu, il s'agit de procéder à une analyse du cycle de vie du réseau des infrastructures, ce qui permet de planifier la maintenance de ces dernières tout au long de leur existence. Cette méthode réunit la planification des infrastructures et l'aménagement urbain et fournit une base quantitative pour des infrastructures durables.

Mots-clés: planification des infrastructures, infrastructures critiques, gestion axée sur la demande et la capacité, développement durable

Michael Neuman, Professor of Sustainable Urbanism, Faculty of the Built Environment, University of New South Wales, Sydney 2052, Australia.

e-mail:m.neuman@unsw.edu.au

\section{Manuskripteingang/received/manuscrit reçu le} 19.1.2011

Annahme zum Druck/accepted for publication/accepté pour publication: 20.7 .2011 